\title{
Pengalaman Ruang Pada Objek Terhadap Kawasan Wisata Kurang Teriamah
}

\author{
Dwimas Maheswara Krisna dan Irvansyah \\ Departemen Arsitektur, Fakultas Teknik Sipil dan Perencanaan, Institut Teknologi Sepuluh Nopember (ITS) \\ e-mail: irvansjah@arch.it.ac.id
}

\begin{abstract}
Abstrak-Desa Sangeh merupakan suatu daerah di Kabupaten Badung Kecamatan Abiansemal yang mendapatkan julukan sebagai desa wisata di Kabupaten Badung. Namun sebagai desa wisata rata-rata pengunjung atau wisatawan baik lokal maupun mancanegara setiap tahunnya berada di titik terendah dari setiap objek-objek wisata yang ada di Kabupaten Badung. Desa Sangeh sendiri kurang memiliki hal yang lebih atraktif untuk menarik wisatawan, wisatawan yang datang ke desa sangeh hanya mengenal Desa Sangeh sebagai monkey forest/hutan kera, sedangkan masih banyak hal lain yang dapat di eksplorasi di Desa Sangeh. Oleh karena itu diperlukan sebuah objek sebagai sebuah pusat yang dapat mengenalkan Desa Sangeh dengan lebih jelas dan lebih informatif. Melalui pendekatan desain yang dilakukan didapatkan program-program yang sesuai dengan tipologi sebuah pusat budaya. Pusat budaya Desa Sangeh bertujuan untuk mengenalkan Desa Sangeh secara lebih detail, dan dapat meningkatkan esensi dari pengalaman ruang yang akan didapat dalam sebuah pusat budaya dengan menstimulus panca indra pada wisatawan. Batasan desain dengan opsi yang cukup banyak serta luasan lahan yang cukup luas menjadikan metode layering sebagai alat untuk mendesain. Layer-layer di tumpuk antara satu dengan yang lain dengan pertimbanganpertimbangan yang sesuai dengan konteks desa sangeh agar tidak melewati batas dari desain lokalitas arsitektur Bali.
\end{abstract}

Kata Kunci-pariwisata, lokalitas, desa wisata, panca indra.

\section{PENDAHULUAN}

$\mathrm{P}$ ARIWISATA merupakan salah satu kebutuhan manusia. Dengan melakukan kegiatan wisata, manusia dapat sejenak melepas penat, lelah dan menghilangkan stress, serta sejenak melupakan masalah yang dialami baik di rumah maupun di kantor. Pariwisata berarti perpindahan orang untuk sementara dan dalam jangka waktu pendek ke tujuan-tujuan di luar tempat di mana mereka biasanya hidup dan bekerja [1]. Bali merupakan sebuah pulau yang telah amat lama menjadi tempat destinasi favorit wisatawan [1]. Namun perkembangan pariwisata di Bali masih terfokus kepada daerah Bali Selatan, banyaknya infrastruktur yang terbangun di daerah Selatan maka keramaian dan tingkat kemacetan yang tinggi pun sering terjadi. Hal ini menyebabkan ada beberapa daerah wisata yang kurang terjamah seperti di kecamatan abiansemal yang terkenal dengan Desa Sangeh dan monkey forest nya (Gambar 2).

Oleh karena itu diperlukan pengembangan terhadap daerah yang kurang terjamah (Gambar 1), dengan cara meningkatkan nilai-nilai budaya, kesenian, kerajinan yang telah ada pada daerah tersebut. Menurut Richards Wisata budaya bisa dibilang menjadi sebuah bentuk 'baik' dari pariwisata, secara luas dipandang sebagai budaya lokal yang berkelanjutan dan mendukung [2].

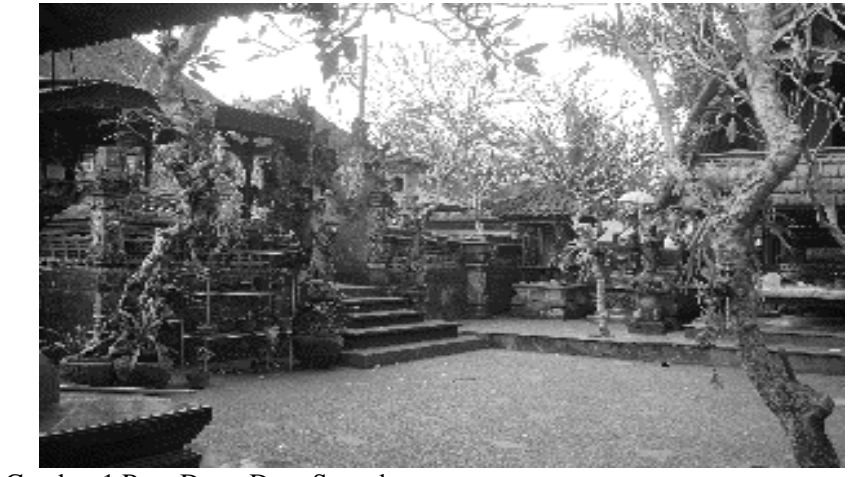

Gambar 1 Pura Desa, Desa Sangeh.

Sumber: Dokumentasi Pribadi

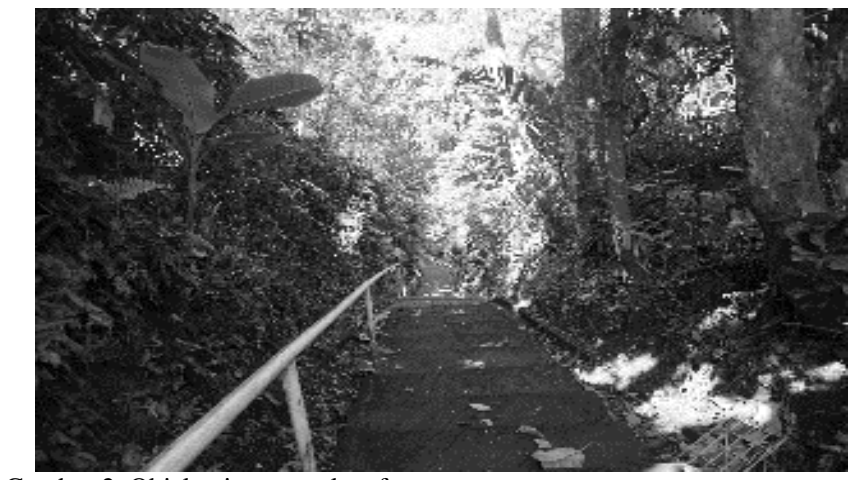

Gambar 2. Objek wisata monkey forest.

Sumber: Dokumentasi Pribadi

\section{METODA PERANCANGAN}

Metoda yang digunakan penulis dalam objek rancangan Pengalaman Ruang Pusat Budaya Desa Sangeh ini adalah metode layering oleh KENGO KUMA dalam bukunya yang berjudul Japanese Layering Pattern beliau menyebutkan bahwa mendesain dengan menggabungkan beberapa layer baik dalam bentuk fisik maupun non fisik akan memunculkan hubungan timbal balik terhadap bentuk sebuah desain dan memunculkan bentuk-bentuk unik dari geometri-geometri yang sudah ber evolusi dan diperkuat dengan layer-layer yang di tumpuk pada satu bagian [3].

Pemakaian metode layering karena didasari dengan adanya Opsi dan pertimbangan desain yang cukup luas, metode layering juga digunakan sebagai alat untuk menemukan bentuk pada Pusat Budaya yang akan di desain. Layer. Bentuk layer non fisik digabungkan dan ditumpuk dengan bentuk layer fisik guna mendapat bentuk yang tidak kaku dan cendrung lebih bebas. Bentuk layer non fisik ditentukan dengan konsep arsitektur bali yang di ambil dari filosofis tri angga (Gambar 5). 


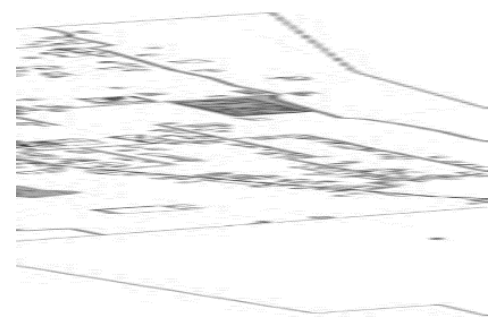

Gambar 4. Peta wilayah objek-objek wisata desa sangeh. Sumber: Dokumentasi Pribadi.

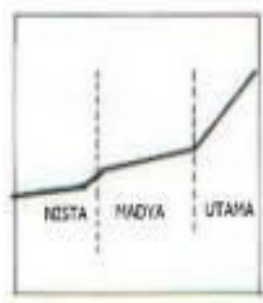

TRA LOKA/TRT ANGGA

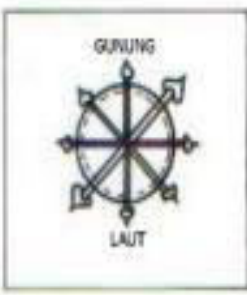

NAWA SANGA/SANGA MAKDaLA

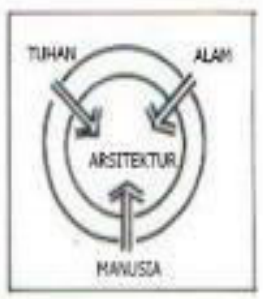

MUNIK RING CECUPU
Gambar 5. Konsep arsitektur bali, diagram filosofis triangga Sumber: kosmologiarsitekturbali

Gambar 6 .layer fisik pertama.

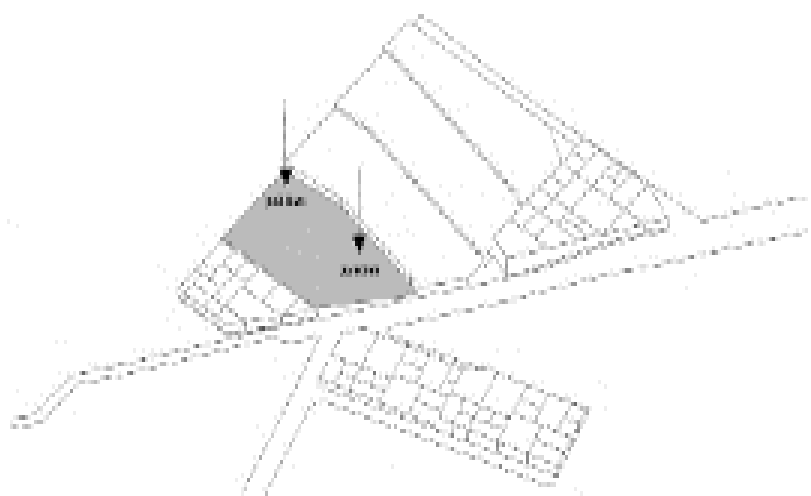

Gambar 7 .layer fisik kedua

Posisi landmark monkey forest yaitu taman mumbul dan monkey forest. Penempatan posisi landmark ini disesuaikan dengan penempatan oleh filosofis triangga tersebut (Gambar 5). Eksplorasi formal dibagi menjadi 7 tahapan diantaranya:

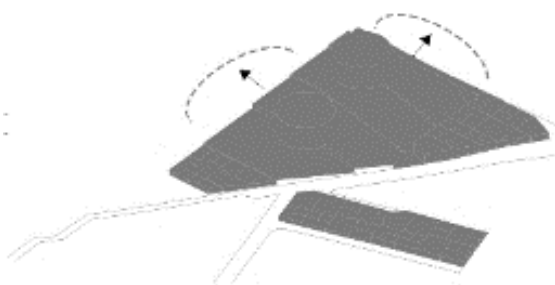

Gambar 8. Layer fisik ketiga

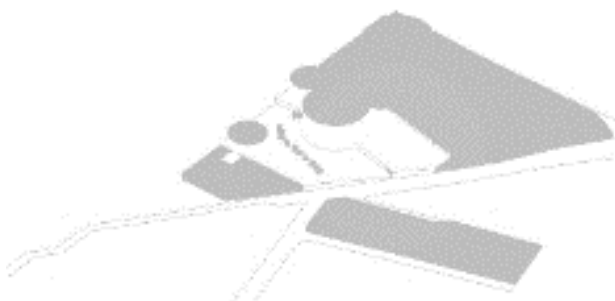

Gambar 9. Layer fisik keempat

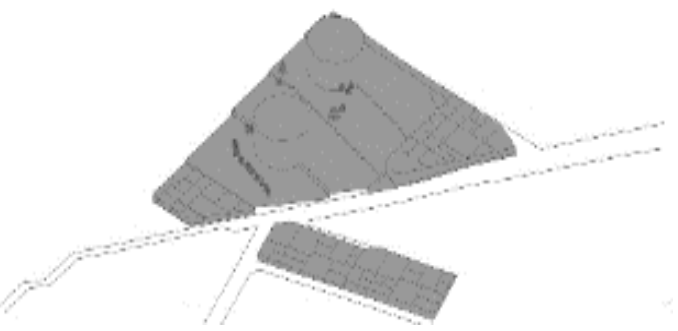

Gambar 10. Layer diamter luas ruang.

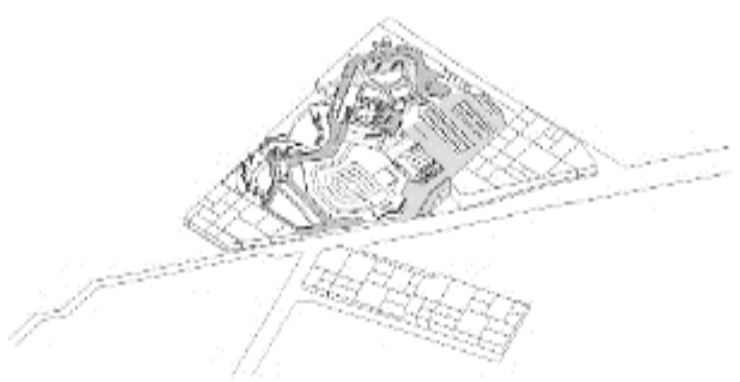

Gambar 11. penentuan jalur dalam penentuan layer

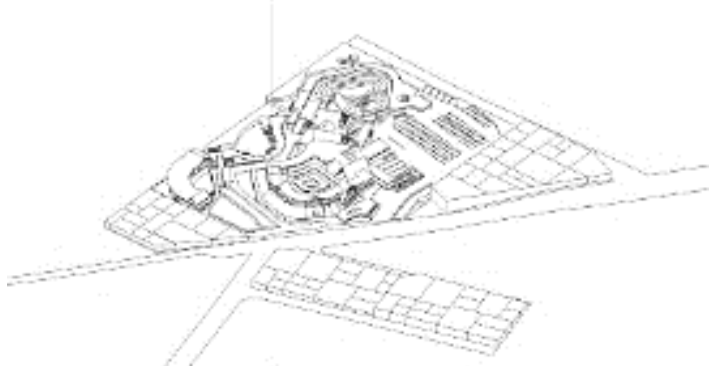

Gambar 12. Hasil penggabungan ke tujuh layer.

- Layer 1

Melihat kondisi sekitar site dengan pertimbangan 2 view (hutan, sawah) pada view atas dan samping kiri. Tinjauan 
view menjadi pertimbangan awal untuk mempertahankan keaslian ppemandangan view dari area sekitar site (Gambar 6).

- Layer 2

Menyamakan level 2 pada kontur ke tahapan level 1 guna mendapatkan posisi yang sejajar dengan jalan raya. Hal ini dilakukan untuk memudahkan akses keluar masuk kendaraan (Gambar7).

- Layer 3

Menyusun massa utama diantaranya menyusun 2 massa utama yang merepresentasikan 2 landmark desa sangeh ke dalam site sebagai bentuk layer nonfisik yang didasari dengan filosofis tri angga. Layer dari filosofi triangga tersebut digabungkan dengan layer dari 2 posisi landmark Desa Sangeh (monkeyforest, dan taman mumbul) (Gambar 8).

- Layer 4

Penentuan alur dari kondisi lahan dan kondisi pohon exising yang tetap berada dalam site. Pohon eksisting

sengaja di biarkan, agar tidak merubah bentuk fisik secara garis besar. (Gambar 9)

- Layer 5

Mengukur volume massa dengan diameter diameter warna pada program-program yang sudah ditentukan. 2 landmark dari Desa Sangeh dijadikan program utama sebagai galeri dan retail. Dari 2 program ini disusupi diameter-diameter kecil sebagai program penunjang (Gambar 10).

- Layer 6

Penentuan jalur service, public, dan kendaraan dari jalur yang sudah ditentukan pada penetapan ayer sebelumnya. Penentuan ketiga jalur ditentukan melalui gelap terang bayangan yang dihasilkan oleh cahaya (Gambar 11).

- Layer 7

Penetapan bentuk massa dan façade dari filosofi gunung. Hasil bentukan didapat setelah menumpuk berbagai opsi serta batasan-batasan desain yang ada, bentuk segitiga dari atap di implementasikan menurut filosofi gunung sebagai atap (triangga) (Gambar 12).

\section{HASIL DAN EKSPLORASI}

Objek rancang merupakan objek yang dapat memberikan warna baru bagi Desa Sangeh. Penambahan objek Pusat Budaya dalam Desa Sangeh bertujuan untuk menginformasikan hal-hal yang masih belum ter ekspos oleh kalangan wisatawan dan untuk menunjukkan kesenian serta kerajinan yang ada didalam Desa Sangeh. Oleh karena itu penulis memilih konsep pengalaman ruang untuk di terapkan ke dalam sebuah rancangan. Pengalaman ruang dibagi 2 berdasarkan 2 landmark yang ada pada Desa Sangeh (Sangeh Monkey Forest, Sangeh Taman Mumbul). 2 landmark dari desa sangeh di implementasikan ke dalam sebuah desain untuk memunculkan identitas desa sangeh di dalam sebuah desain. Tujuan dari implementasi 2 buah landmark desa sangeh untuk memberikan kesan keaslian desa sangeh dalam sebuah desain. Pendekatan desain Behaviour/perilaku dlakukan penulis untuk mempermudah dan mengetahui perilaku dari wisatawan dan mendapatkan program desain yang ideal kterhadap rancangan. Implementasi Konsep Pengalaman Ruang dalam rancangan:

- Interior dalam galeri di desain dengan dasaran bentuk dan pattern yang telah digunakan dan dengan mengemphasis daerah kawasan monkey forest sangeh dengan tujuan untuk menstimulus rasa dan membangkitan serta mengembangkan pengalaman pada ruang seperti monkey forest pada aslinya (Gambar 14).

- Interior galeri pada level dua/lantai dua di desain secara open/terbuka dengan tujuan agar pengunjung dapat menikmati kondisi seperti di dalam hutan dengan cara melihat dan berjalan dalam koridor seperti melewati lorong dalam hutan monkey forest. Lorong disini berfungsi untuk menciptakan rasa/sense yang mensitimulus indra peraba. Indera peraba di stimulus melalui permainan cahaya (Gambar 13).

Bagian luar desain pusat budaya lebih mengarah kepada desain landscape, desain landscape ini merupakan emphasis dari landmark taman mumbul yang merupakan salah satu landmark dari desa sangeh. Tujuan dibuatnya kolam besar pada daerah retail adalah untuk merepresentasikan taman air yang ada di taman mumbul (Gambar 15).

\section{KESIMPULAN}

Melalui pendekatan behavior/perilaku yang digunakan untuk mengetahui program yang baik untuk perilaku wisatawan, desain pusat budaya dengan pengalaman ruang di harapkan dapat membantu dessa sangeh meningkatkan ratarata pengunjung pertahun dengan menghadirkan sesuatu yang dapat membangkitkan rasa serta pengalaman ruang dalam sebuah desain. Serta metode layering oleh kengo kuma yang di gunakan untuk membahas serta menyelesaikan isu, batasan desain tentang daerah wisata kurang terjamah pada desa sangeh, dapat menjadikan objek wisata desa sangeh menjadi sebuah desain yang memiliki ciri khas yang tetap berkaitan dengan batasan arsitektur bali. Dengan di hadirkannya sebuah objek wisata berupa pusat budaya desa sangeh, segala warisan kesenian dan karya dari warga sekitar dapat tersalurkan dan terinformasikan secara lebih detail dalam sebuah pusat budaya. Desain pusat budaya dengan pengalaman ruang diharapkan dapat menjawab hal-hal yang menyebabkan desa sangeh menjadi kurang terjamah.

\section{DAFTAR PUSTAKA}

G. Richards and J. Wilson, Tourism, Creativity, and Development. 2003

[2] Burkart and S. Malik, Tourism, Past,Present, and Future. 1981.

[3] K. Kuma, Japanese Spatial Culture, Nature, and Architecture. 2000. 